\title{
Announcement of the Prof. Yu.I. Ostrovskiir Prize Competition 2008
}

DOI: $10.1134 /$ S106378420801026X

The Ioffe Physicotechnical Institute and Rossiya Bank announce the next regularly scheduled competition for the Prof. Yu.I. Ostrovskiı̂ Prize. The prize was established in memory of the founder of the Russian school of holographic interferometry and is awarded for prominent works in the field of optical holography and interferometry.

In accordance with the prize regulations, two prizes are awarded: the first prize amounting to $66.7 \%$ and the second one amounting to $33.3 \%$ of the bonus fund (30000 roubles).

Admitted to the competition are authors who accomplished their studies on the territory of the Russian Federation and published the results in Russian and foreign journals in the five years before the year of the competition, that is, over the period from 2003 to
2007. The competition committee reserves the right to let works that were submitted for the previous competitions and did not win take part in the present competition, provided that they meet the terms of publication.

Papers submitted for the Ostrovskiı Competition 2008, along with a summary and information about the author(s), should be sent (all in three copies) to Competition Committee Secretary G.V. Drě̆den, Ioffe Physicotechnical Institute, Russian Academy of Sciences, Politekhnicheskaya ul. 26, St. Petersburg, 194021 Russia.

The submission deadline is March 31, 2008.

For more information, please contact us by phone (812)292-7185 or 316-1809; e-mail: galina.dreiden@mail.ioffe.ru 